Check for updates

Cite this: RSC Adv., 2020, 10, 42212

Received 3rd August 2020

Accepted 15th November 2020

DOI: $10.1039 / \mathrm{dOra06700h}$

rsc.li/rsc-advances

\section{An electrochemical sensor based on copper-based metal-organic framework-reduced graphene oxide composites for determination of 2,4- dichlorophenol in water $\dagger$}

\author{
Manh B. Nguyen, $t^{a}$ Vu Thi Hong Nhung, $t^{a}$ Vu Thi Thu, (D) *b Dau Thi Ngoc Nga, ${ }^{b}$ \\ Thuan Nguyen Pham Truong, ${ }^{c}$ Hoang Truong Giang, (ID) ${ }^{b}$ Pham Thi Hai Yen, ${ }^{a}$ \\ Pham Hong Phong, ${ }^{a}$ Tuan A. Vu ${ }^{a}$ and Vu Thi Thu Ha (D) *ab
}

\section{Introduction}

The analysis of phenolic compounds in natural waters and effluents is a strategic subject in environmental control. Phenolic compounds usually coexist in environmental samples and are toxic to animals and aquatic organisms. Both the European Union and US Environmental Protection Agency ${ }^{1}$ consider 2,4-dichlorophenol (2,4-DCP) as a priority pollutant with an admissible concentration in water of $0.5 \mathrm{ng} \mathrm{mL} \mathrm{m}^{-1}$ and it is harmful to human health even at a very low concentration. ${ }^{2}$ Therefore, this compound has received a great interest and it is certainly necessary to develop a simple, fast, sensitive and accurate analytical methods for its detection in environment. For this purpose, many methods have been developed and

${ }^{a}$ Institute of Chemistry (IoC), Vietnam Academy of Science and Technology (VAST), 18 Hoang Quoc Viet, Cau Giay, Hanoi, Vietnam.E-mail: Havt@ich.vast.vn

${ }^{b}$ University of Science and Technology of Hanoi (USTH), Vietnam Academy of Science and Technology (VAST), 18 Hoang Quoc Viet, Cau Giay, Hanoi, Vietnam. E-mail: thuvu.edu86@gmail.com

${ }^{c}$ CY Cergy Paris University, LPPI, 5 Mail Gay Lussac, F-95000, Cergy, France

$\dagger$ Electronic supplementary information (ESI) available. See DOI: 10.1039/d0ra06700h

\$ These authors provided equal contribution to this work. published, such as gas chromatography, ${ }^{3}$ liquid chromatography, ${ }^{4} \mathrm{UV}$-spectrophotometry, ${ }^{5}$ chemiluminescence ${ }^{6}$ and electrochemical techniques. Among them, the electrochemical methods were more and more interested as they are able to provide low detection limit (LODs), high selectivity and wide linear ranges with no expensive equipment required. Moreover, the equipment is able to perform analysis on-site, therefore, this is very useful for environmental monitoring.

Many applications of the electrochemical detection of 2,4DCP has been reported using various modified electrodes. J. Zhang et al. used molecularly imprinted polymer (MIP) adherenced on $\mathrm{GCE}^{7}$ while a ternary composite of diamond, graphene and polyaniline (DGP) ${ }^{8}$ was used as an electrode modifier. With the later modifier, the peak current of 2,4-DCP is visually increased which is explained by the enhancement of electroactive surface of the electrode. Other modifiers have been developed such as $\beta$-cyclodextrin functionalized ionic liquid, ${ }^{9}$ enzymatic amplified on graphene membrane,${ }^{10}$ molybdenum disulfide, ionic liquid and gold/silver nanorods ${ }^{11}$ metal organic framework $\mathrm{Cu}_{3}(\mathrm{BTC})_{2}$ carbon paste electrode ${ }^{12}$ etc.

In the last decade, much effort has been devoted to the integration of Metal-Organic Frameworks (MOFs) based on transition metals onto electrochemical sensing platforms. The 
focal metals $(\mathrm{Zn}, \mathrm{Mn}, \mathrm{Ni}, \mathrm{Cu})$ in framework acts as active sites to accelerate electrocatalytic reactions whereas organic ligands (1,4-benzene dicarboxylate (BDC), 1,3,5-benzene tricarboxylate (BTC), 4,4',4"-benzene-1,3,5-triyl-tribenzoate (BTB)) act as adsorption sites towards target organic molecules. ${ }^{13}$ As a classical MOFs material, Cu-BTC has been widely used in various fields such as gas storage, catalysts and energy materials, ${ }^{\mathbf{1 4}}$ however, its application in electrochemical sensors are still being interested of scientists. Yu Cao et al. developed an electrochemical sensor on the hierarchically porous Cu-BTC MOF platform for glyphosate determination. ${ }^{15} \mathrm{Ji}$ et al. prepare $\mathrm{Cu}-$ BTC frameworks as a novel detection platform for sunset yellow and tartrazine. ${ }^{\mathbf{1 6}} \mathrm{A} \mathrm{Cu}-\mathrm{MOF} /$ graphene composite has been used for determination of dopamine and paracetamol, ${ }^{17} \mathrm{Cu}$-based metal-organic framework $\left[\mathrm{Cu}_{3}(\mathrm{BTC})_{2}\left(\mathrm{H}_{2} \mathrm{O}\right)_{3}\right]_{n}$ for catechol ${ }^{18}$ and MOF 199-GO- $n / \mathrm{GCE}$ for catechol and hydroquinone. ${ }^{19}$ Dihydroxylbenzene has been detected in water by using an electrochemical sensor based on $\mathrm{Cu}-\mathrm{MOF}-\mathrm{GN}$ composites. ${ }^{20}$ As Sheying Dong. ${ }^{12}$ reports an application of $\left[\mathrm{Cu}_{3}(\mathrm{BTC})_{2}\right]$ as a modifier for carbon paste electrode to detect 2,4-DCP and the authors attribute the high sensitivity of the modified electrode to the large surface area, high adsorption capacity and good electron transfer efficiency of the $\left[\mathrm{Cu}_{3}(\mathrm{BTC})_{2}\right]$. Sensitivity and detection limit achieve $0.159 \mu \mathrm{A} \mu \mathrm{M}^{-1}$ and $0.009 \mu \mathrm{M}$ respectively in this case. Although MOFs provide a large surface area, high adsorption capacity and good electron transfer efficiency, their disadvantages are known as having low electric conductivity. A simple and efficient strategy to improve the conductivity is to use the mixture of MOFs and some conductive materials, such as carbon materials. "' "Graphene and graphene oxide (GO) have been used as substrates for immobilizing and/or conducting the nucleation and growth of MOFs". ${ }^{22}$ Wang et al. reported that graphene oxide (GO) was torn into small fragments to participate in the formation of HKUST-1 composite (HKUST-1 is a copper-based metal-organic framework also known as MOF-199 or Cu-BTC). Their study showed that the composite greatly increased the redox-activity, surface area and electrical conductivity. ${ }^{23}$ Camille et al. also demonstrated the synergetic effect between the GO and MOF, including porosity increasing and adsorption enhancement. ${ }^{24}$ The MOF-rGO combination not only facilitate the utilization of the other active materials, but also enhances the mechanical strength and conductivity of the materials synergistically. ${ }^{25}$ In this papers, the $\mathrm{Cu}-\mathrm{BTC} / \mathrm{GO}$ was synthesized by a simple method and used as the electrode material for sensitive detection of 2,4-DCP.

\section{Experimental}

\subsection{Materials}

Benzene-1,3,5-tricarboxylic acid, ( $\left.\mathrm{H}_{3} \mathrm{BTC}, 98 \%\right), \mathrm{CuCl}_{2} \cdot 2 \mathrm{H}_{2} \mathrm{O}$ (97\%), $\mathrm{NaOH}(98 \%), \mathrm{KH}_{2} \mathrm{PO}_{4}, \mathrm{~K}_{2} \mathrm{HPO}_{4}, \mathrm{C}_{2} \mathrm{H}_{5} \mathrm{OH}$ (96\%), potassium ferrocyanide trihydrate $\left(\mathrm{K}_{4}\left[\mathrm{Fe}(\mathrm{CN})_{6}\right] \cdot 3 \mathrm{H}_{2} \mathrm{O}\right)$ and potassium ferricyanide $\left(\mathrm{K}_{3}\left[\mathrm{Fe}(\mathrm{CN})_{6}\right]\right)$ were all purchased from SigmaAldrich. All chemicals were used as received without any further treatments.

2,4-Dichlorophenol (2,4-DCP) was purchased from SigmaAldrich (structures in Fig. 1S $\dagger$ ). Glassy carbon (GCE) (BAS, diameter $=3 \mathrm{~mm}$ ) was used as current collector. Phosphate buffer solution (PBS) was prepared by mixing $0.1 \mathrm{M} \mathrm{KH}_{2} \mathrm{PO}_{4}$ and $0.1 \mathrm{M} \mathrm{K}_{2} \mathrm{HPO}_{4}$ until a desired $\mathrm{pH}$ (in the range from 6.0 to 8.0) was obtained.

\subsection{Synthesis of nano $\mathrm{Cu}-\mathrm{BTC} / \mathrm{GO}$ composites}

Graphene oxide (GO) was synthesized according to modified Hummer method. ${ }^{26}$ Briefly, $1.0 \mathrm{~g}$ of graphite flakes were transferred into a mixture of $150 \mathrm{~mL}$ concentrated $\mathrm{H}_{2} \mathrm{SO}_{4}$ and $\mathrm{H}_{3} \mathrm{PO}_{4}$ $(4: 1, \mathrm{v} / \mathrm{v}(\%))$, stirred at room temperature for $1 \mathrm{~h}$ then $6.0 \mathrm{~g}$ of $\mathrm{KMnO}_{4}$ was added slowly in the solution. The mixture was kept at room temperature for 3 days. Afterward, color of this mixture was turned from dark green to dark brown. The oxidation reaction was quenched using $600 \mathrm{~mL}$ ice-cold water and $3 \mathrm{~mL} \mathrm{H}_{2} \mathrm{O}_{2}$ (30 wt\%). The color of the solution was changed into bright yellow then it was centrifuged and washed with $1 \mathrm{M} \mathrm{HCl}$ to remove excess manganese salt. Finally, it was washed with distilled water until neutral $\mathrm{pH}$ obtained then dried at $100{ }^{\circ} \mathrm{C}$ overnight. The dried compound graphene oxide was labeled as GO.

The synthesis procedure of $\mathrm{Cu}-\mathrm{BTC} / \mathrm{GO}$ is as followed: $2.05 \mathrm{~g}$ of $\mathrm{CuCl}_{2} \cdot 2 \mathrm{H}_{2} \mathrm{O}$ was dissolved in $97.2 \mathrm{~mL}$ of distilled water (solution 1) and $1.68 \mathrm{~g}$ of $\mathrm{H}_{3}$ BTC was added into $23.72 \mathrm{~mL}$ of a $1 \mathrm{M} \mathrm{NaOH}$ solution (solution 2). Both solutions above were kept under stirring until obtaining clear solutions. The solution (2) was added dropwise to the solution (1) with stirring for $1 \mathrm{~h}$ until the mixture turned from green to brown color. Then, $0.8 \mathrm{~g}$ of GO was added into the mixture and stirred for $0.5 \mathrm{~h}$ at room temperature. Finally, the obtained mixture was poured into a Teflon bottle and heated in a microwave furnace $(700 \mathrm{~W})$ at $100{ }^{\circ} \mathrm{C}$ for 30 minutes. The product was collected by centrifugation at $8000 \mathrm{rpm}$ for $5 \mathrm{~min}$ and washed with distilled water (three times) and finally with ethanol (once). The solid product was turned in brown color after drying in a furnace at $80{ }^{\circ} \mathrm{C}$, overnight.

\subsection{Characterization of synthesized $\mathrm{Cu}-\mathrm{BTC} / \mathrm{GO}$}

The crystalline phase structure of as-prepared materials was determined over the 2-theta range of $2-50^{\circ}$ (D8 ADVANCE, Bruker, Germany) using a $\mathrm{Cu} \mathrm{K}_{\alpha 1}$ copper radiation $(\lambda=0.154$ $\mathrm{nm}$ ) as the X-ray source at a scan rate of $2^{\circ} \mathrm{min}^{-1}$. FT-IR spectra are recorded on a Bruker TENSOR37 instrument. Scanning electron microscopy images are conducted on a JSM 740, operating at an accelerating voltage of $200 \mathrm{kV}$. Energy-dispersive $\mathrm{X}$-ray spectroscopy analysis (EDX) was measured on a JED-2300 with gold coating. The Brunauer-Emmett-Teller (BET) surface areas of the samples were evaluated by the $\mathrm{N}_{2}$ adsorption isotherm at $77 \mathrm{~K}$ using a BET Sorptometer (Automated Sorptometer BET 201-A, USA). TGA data were recorded on the LABSYS evo TG-DTA 1600. X-ray photoelectron spectroscopy (XPS) was measured using a Thermo ESCALAB spectrometer (USA) employing a monochromic $\mathrm{Al} \mathrm{K} \alpha$ source at $1486.6 \mathrm{eV}$. Software used in this case was "Avantage" (purchased from Thermo Fisher Scientific). The deconvolution is performed as followed: the background was generated by using Smart background from the Avantage which is based on the Shirley background with additional condition that the background's values could not exceed the input data at any point in the measured window. The 
spectrum was fit using the function "Peak fitting" which allows an automatic adjustment of shape parameters (height, width, ratio Gaussian/Lorentzian).

All electrochemical measurements were performed with an AUTOLAB potentiostat PGS302N (Metrohm, Netherland) equipped with a three-electrode configuration, where an $\mathrm{Ag} / \mathrm{AgCl} / \mathrm{Sat}$. $\mathrm{KCl}$ and a Pt wire was used as the reference and counter electrodes, respectively, and modified $\mathrm{Cu}-\mathrm{BTC} / \mathrm{GO}$ electrode was employed as the working electrode. All experiments in this study were performed at room temperature $\left(25 \pm 1{ }^{\circ} \mathrm{C}\right)$.

\subsection{Preparation of $\mathrm{Cu}-\mathrm{BTC} / \mathrm{GO} / \mathrm{GCE}$}

Prior to the modification, the GCE surface ( $3 \mathrm{~mm}$ diameter) was polished with $0.5 \mathrm{~mm}$ alumina slurries, rinsed thoroughly with double distilled water, sonicated $3 \mathrm{~min}$ in acetone and $3 \mathrm{~min}$ in water, and dried at room temperature. Three suspensions of $\mathrm{Cu}$-BTC/GO were prepared by dispersing $0.5,1.0$ and $3.0 \mathrm{mg}$ of as-synthetized composite, respectively, in $1 \mathrm{~mL}$ of ethanol using ultrasonic stirring for $30 \mathrm{~min}$. A droplet of $5 \mu \mathrm{L}$ of this dispersion was coated on the well prepared GCE surface and then ethanol was evaporated at room temperature to form $\mathrm{Cu}-\mathrm{BTC} /$ GO/GCE in about 1 hour. Finally, the modified electrode was thoroughly rinsed with distilled water and placed into the electrochemical cell. Before use, $\mathrm{Cu}-\mathrm{BTC} / \mathrm{GO} / \mathrm{GCE}$ was electrochemical reduced by applying a potential of $-1.5 \mathrm{~V}$ for $300 \mathrm{~s}$ in PBS 0.1 M (pH = 7). This electrode was denoted as $\mathrm{Cu}-\mathrm{BTC} /$ ErGO/GCE.

\subsection{Optimization of sensor operating conditions}

The detection of 2,4-DCP was carried out in aqueous media using differential pulse voltammetry (DPV) method with a differential step of $0.005 \mathrm{~V}$, a sampling time of $0.04 \mathrm{~s}$, a pulse width of $0.08 \mathrm{~s}$ and a pulse amplitude of $0.05 \mathrm{~V}$. To improve the effectiveness of sensing performances, some experimental conditions were optimized. Initially, the optimization of the content of $\mathrm{Cu}-\mathrm{BTC} / \mathrm{GO}$ at $0.5,1.0$ and $2.0 \mathrm{mg} \mathrm{mL}^{-1}$ solvent used for modification in $0.1 \mathrm{M}$ PBS $(\mathrm{pH}=7.0)$ at $2,4-\mathrm{DCP}$ concentration of $2 \mathrm{ppm}$ with accumulation time of $240 \mathrm{~s}$. The effect $\mathrm{pH}$ (6.0, 6.5, 7.0, 7.5 and 8.0) on the electrochemical signals of 2,4DCP in 0.1 M PBS was also tested. The accumulation conditions of 2,4-DCP onto $\mathrm{Cu}-\mathrm{BTC} / \mathrm{ErGO} / \mathrm{GCE}$ were conducted at $i=$ 0 (under open-circuit potential) with accumulation time of $60 \mathrm{~s}$, $120 \mathrm{~s}, 180 \mathrm{~s}, 240 \mathrm{~s}, 360 \mathrm{~s}, 420 \mathrm{~s}$ and $480 \mathrm{~s}$. The optimal operating conditions will be selected for sensing performances of asprepared sensors towards interested analyte in further experiments.

\section{Results and discussion}

\subsection{Chemical composition and structural behaviors of $\mathrm{Cu}-$ BTC/GO}

The chemical composition of the $\mathrm{Cu}-\mathrm{BTC} / \mathrm{GO}$ material and valance state of copper were evaluated from XPS spectra (Fig. 1).

As seen from XPS survey spectrum (Fig. 1(a)), the Cu-BTC/ GO is mainly composed of carbon (at 74.75\%), oxygen (at $21.98 \%$ ), and copper (at $3.27 \%$ ) as expected. The high-
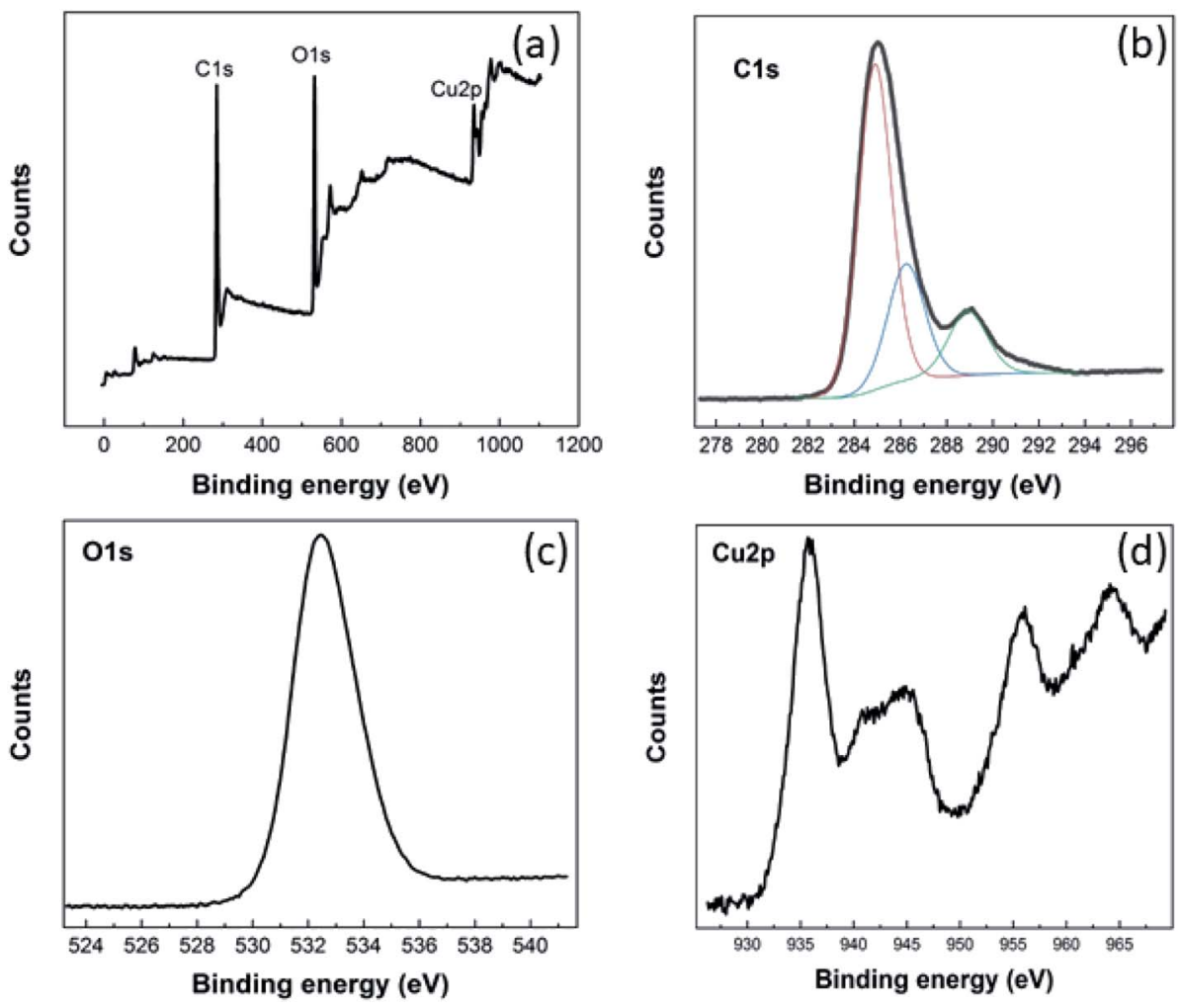

Fig. 1 XPS survey (a) and high-resolution C 1s (b), O 1s (c), Cu 2p (d) of Cu-BTC/GO powder. 


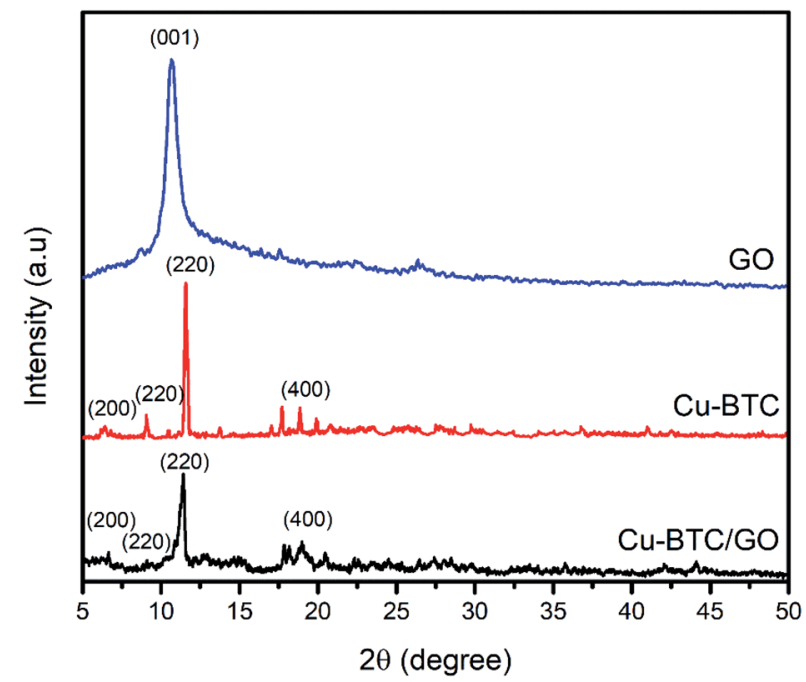

Fig. 2 XRD patterns of GO, Cu-BTC and Cu-BTC/GO sample.

resolution $\mathrm{C}$ 1s spectrum (Fig. 1(b)) shows one main peak at $284.9 \mathrm{eV}$ and three other peaks at higher binding energies. The main peak in $\mathrm{C}$ 1s XPS spectrum is probably attributed to $\mathrm{C}-\mathrm{C}$ and $\mathrm{C}=\mathrm{C}$ bonds in honeycomb structure of $\mathrm{rGO}$, and in aromatic rings of organic ligands (BTC). The three other peaks arise from the oxygenated functional groups such as $\mathrm{C}-\mathrm{OH}$ $(286.2 \mathrm{eV}), \mathrm{C}=\mathrm{O}(288.9 \mathrm{eV})$, and $\mathrm{O}=\mathrm{C}-\mathrm{OH}(291.1 \mathrm{eV}) .{ }^{27}$ The high-resolution $\mathrm{O} 1 \mathrm{~s}$ (Fig. 1(c)) reveals one unique peak at $532.5 \mathrm{eV}$ which is ascribed to oxygen bonding in the crystalline network ${ }^{28}$ as well as residual $\mathrm{O}$ bonding in rGO. Cu 2p XPS spectrum (Fig. 1(d)) presents the main peaks of copper $\left(\mathrm{Cu} 2 \mathrm{p}_{3 / 2}\right.$ peak at $935.8 \mathrm{eV} ; \mathrm{Cu} 2 \mathrm{p}_{1 / 2}$ peak at $955.8 \mathrm{eV}$ ) and the their satellite peaks $\left(\mathrm{Cu} 2 \mathrm{p}_{3 / 2}\right.$ satellite at $944.6 \mathrm{eV} ; \mathrm{Cu} 2 \mathrm{p}_{1 / 2}$ satellite at $964.2 \mathrm{eV}$ ) which corresponds to copper(II), ${ }^{29}$ but not copper(I), ${ }^{30}$ copper metal, or copper oxides. ${ }^{31}$ XPS spectra recorded for pure GO was given in the below figures and will be added to ESI (as Fig. $2 \mathrm{~S}^{\dagger}$ ). It can be seen that there is no signal relevant to $\mathrm{Cu}$ element in GO sample. In the same time, there are two peaks in $\mathrm{O} 1 \mathrm{~s}$ spectrum at $533 \mathrm{eV}$ and $536 \mathrm{eV}$ which are characteristic for GO material.

XRD pattern of $\mathrm{Cu}-\mathrm{BTC}$ and $\mathrm{Cu}-\mathrm{BTC} / \mathrm{GO}$ represents the peaks at $2 \theta$ of $6.56^{\circ}, 9.32^{\circ}, 11.2^{\circ}$, and $18.92^{\circ}$ which are assigned to (200), (220), (222) and (440) reflection planes, respectively. ${ }^{32}$ In the XRD patterns of composites (Fig. 2), there is no characteristic peak of GO, the reason probably lies in the fact that the peak of GO appeared at $2 \theta$ of $11-12^{\circ}$ but this peak is overlapped by the peak at (222) plane located at $2 \theta$ of $11.2^{\circ}$. The XRD pattern of $\mathrm{Cu}-\mathrm{BTC} / \mathrm{GO}$ showed similar diffraction peaks to bare $\mathrm{Cu}-\mathrm{BTC},{ }^{33}$ confirming that the addition of GO does not affect the crystal structure of $\mathrm{Cu}-\mathrm{BTC} .^{34}$

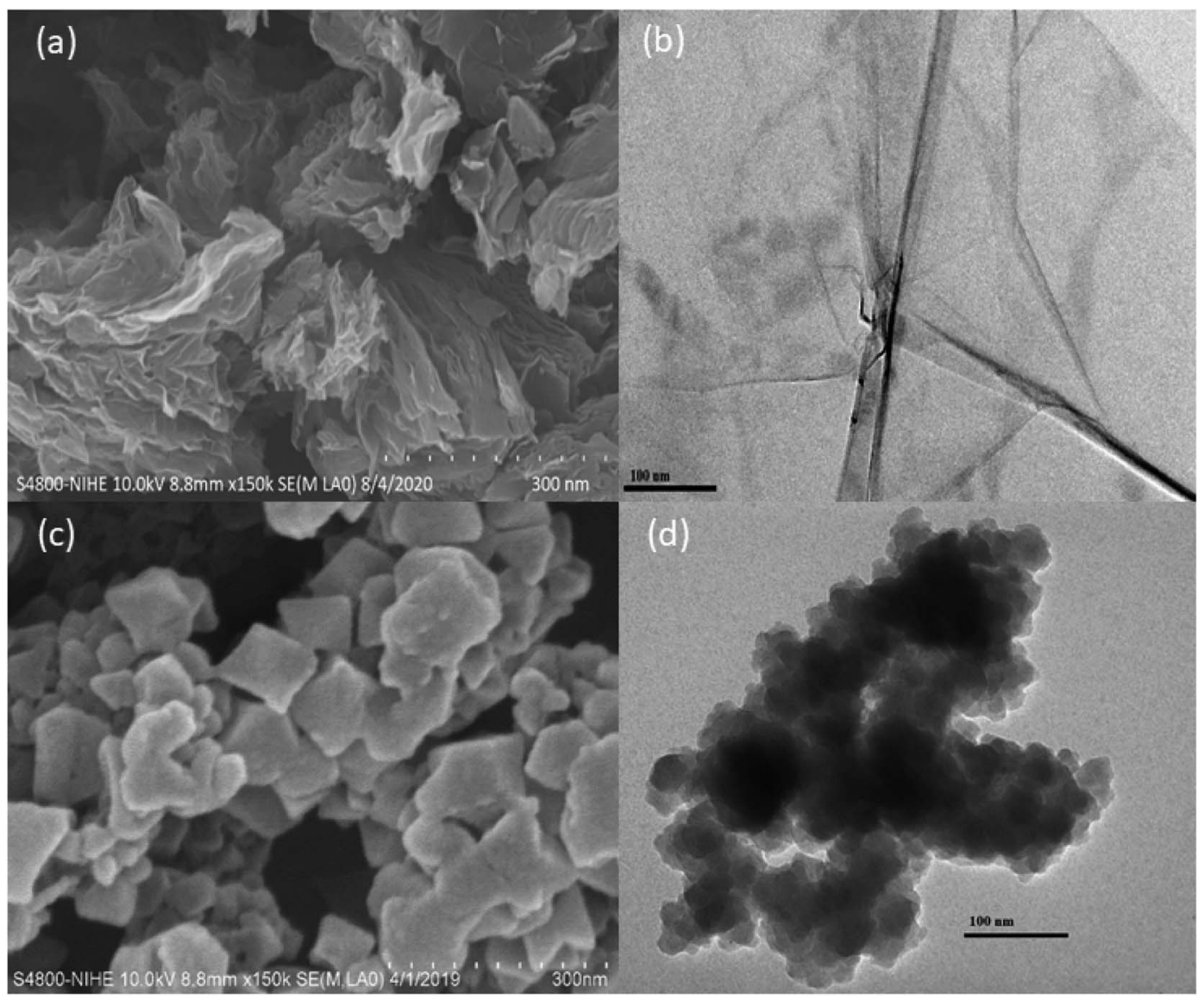

Fig. 3 SEM and TEM images of ( $a$ and b) GO and (c and d) of Cu-BTC/GO samples. 


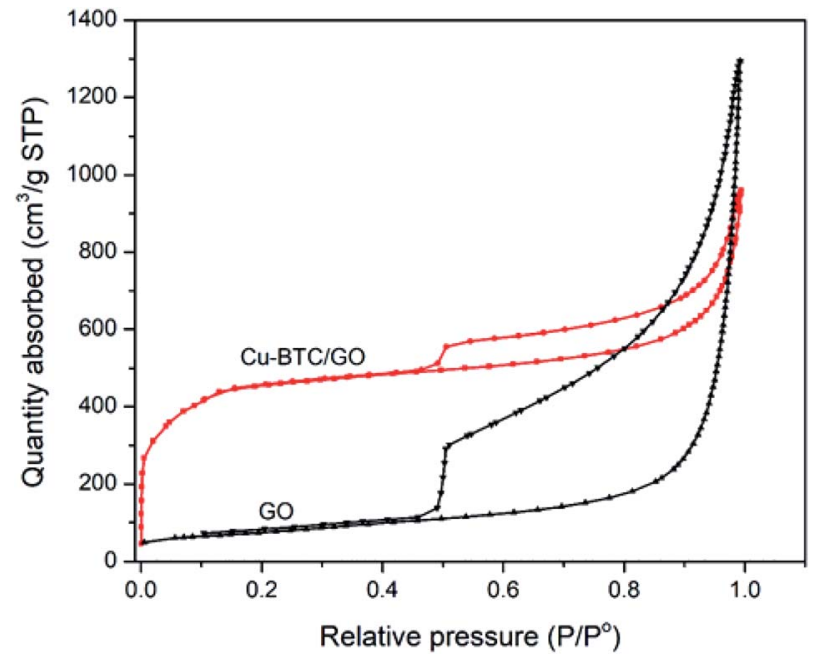

Fig. $4 \mathrm{~N}_{2}$ adsorption-desorption isotherms of $\mathrm{GO}$ and $\mathrm{Cu}-\mathrm{BTC} / \mathrm{GO}$

The FTIR spectra of GO and Cu-BTC/GO is shown in Fig. 3S. $\dagger$ In the spectrum of $\mathrm{Cu}-\mathrm{BTC} / \mathrm{GO}$, appeared the bands at $1735 \mathrm{~cm}^{-1}$ and $1630 \mathrm{~cm}^{-1}$ which assigned to the vibration of $\mathrm{C}=\mathrm{O}$ and carboxylic acid groups, respectively. The bands at $1405 \mathrm{~cm}^{-1}$ and $1210 \mathrm{~cm}^{-1}$ attributed to the vibration of $\mathrm{C}-\mathrm{OH}$, $\mathrm{C}-\mathrm{O}-\mathrm{C}$ and $\mathrm{C}-\mathrm{O}$ groups, respectively. The band at $3414 \mathrm{~cm}^{-1}$ is assigned to the vibration of $\mathrm{OH}$ groups that existed in ligands and water. The bands at $1630 \mathrm{~cm}^{-1}, 1570 \mathrm{~cm}^{-1}, 1449 \mathrm{~cm}^{-1}$ and $1382 \mathrm{~cm}^{-1}$ are attributed to the vibrations of $\mathrm{C}=\mathrm{O}, \mathrm{C}-\mathrm{C}, \mathrm{C}-\mathrm{O}$ groups, respectively. ${ }^{35}$ The bands at $760 \mathrm{~cm}^{-1}, 725 \mathrm{~cm}^{-1}$ and $1110 \mathrm{~cm}^{-1}$ are attributed to the oscillation of $\mathrm{Cu}-\mathrm{O}$ bonds. ${ }^{33}$ The absorption peak at $1110 \mathrm{~cm}^{-1}$ is characteristic of $\mathrm{Cu}-\mathrm{BTC}$ with the bond of $\mathrm{C}-\mathrm{O}-\mathrm{Cu} .^{33}$

SEM images (a) and TEM image (b) of $\mathrm{Cu}-\mathrm{BTC} / \mathrm{GO}$ are illustrated in Fig. 3. As observed in Fig. 3, the crystal size of Cu-BTC/ GO composites was ranged in $60-80 \mathrm{~nm}$ with uniform distribution. The particle size to $60-80 \mathrm{~nm}$ when the $\mathrm{Cu}-\mathrm{BTC}$ crystals are grown and assembled on the GO sheet. $\mathrm{Cu}-\mathrm{BTC}$ nanoparticles adhere firmly to GO substrate to form a free-standing state composite nanosheet with a sandwich structure.

EDX spectrum and EDX mapping image of GO and Cu-BTC/ GO were shown in Fig. $4 \mathrm{~S} . \dagger$ The element content (wt\%) of graphene oxide sample with $\mathrm{C}$ and $\mathrm{O}$ were 76.49 and $23.51 \%$, respectively (Fig. $4 \mathrm{~S}(\mathrm{a})$ ). $\dagger$ As seen in Fig. $4 \mathrm{~S}(\mathrm{~b}), \dagger$ the element content (wt\%) of $\mathrm{C}, \mathrm{O}$ and $\mathrm{Cu}$ were 56.48, 25.24 and $18.28 \%$, respectively. EDX mapping image of $\mathrm{Cu}-\mathrm{BTC} / \mathrm{GO}$ showed the $\mathrm{Cu}-$ BTC particle size of Ca. 50-80 nm with uniform distribution.

\section{2. $\mathbf{N}_{2}$ adsorption-desorption isotherms of $\mathrm{Cu}-\mathrm{BTC} / \mathrm{GO}$}

$\mathrm{N}_{2}$ adsorption-desorption isotherms of $\mathrm{Cu}-\mathrm{BTC} / \mathrm{GO}$ samples have a type IV delay curves according to the IUPAC classification. The $\mathrm{N}_{2}$ adsorption-desorption isotherms (Fig. 4) at a low partial pressure of 0.4-1.0 appeared the hysteresis loop, which is often observed on mesoporous materials. This behavior is due to the capillary condensation of $\mathrm{N}_{2}$ at high partial pressure. The $\mathrm{N}_{2}$ adsorption-desorption isotherms of GO showed a larger hysteresis loop as compared to that of $\mathrm{Cu}-\mathrm{BTC} / \mathrm{GO}$. This can be explained by the fact that space between GO are empty, favoring the capillary condensation of $\mathrm{N}_{2}$ while $\mathrm{Cu}-\mathrm{BTC} / \mathrm{GO}$ showed smaller hysteresis loop due to the filling up the $\mathrm{Cu}$-BTC particles within the GO layers. Note that $\mathrm{Cu}-\mathrm{BTC}$ is a microporous material, there is no the capillary condensation of $\mathrm{N}_{2}$ due to the small pore of $0.5-0.8 \mathrm{~nm}$. The surface area, pore volume and pore size of GO were $264 \mathrm{~m}^{2} \mathrm{~g}^{-1}, 2.02 \mathrm{~cm}^{3} \mathrm{~g}^{-1}$ and $8.95 \mathrm{~nm}$, respectively. The surface area, pore volume and pore size of $\mathrm{Cu}-\mathrm{BTC} / \mathrm{GO}$ were $1591 \mathrm{~m}^{2} \mathrm{~g}^{-1}, 1.485 \mathrm{~cm}^{3} \mathrm{~g}^{-1}$ and $3.34 \mathrm{~nm}$, respectively.

\subsection{Thermogravimetric analysis (TGA) and differential thermal analysis (DTA)}

The thermal stability of $\mathrm{Cu}-\mathrm{BTC} / \mathrm{GO}$ composite with respect to temperature was studied by TGA (Fig. $5 \mathrm{~S} \dagger$ ). As seen Fig. $5 \mathrm{~S} \dagger$ the initial weight loss of $24.03 \%$ at $100{ }^{\circ} \mathrm{C}$ can be attributed to loss of moisture which continues up to $150{ }^{\circ} \mathrm{C}$. The weight loss of $55.09 \%$ from 250 to $550{ }^{\circ} \mathrm{C}$ is may be due to decomposition of organic benzene tricarboxylate linker and collapsing of MOF structure. From TGA diagram, an intense peak at $360.53{ }^{\circ} \mathrm{C}$ appeared. This indicated the exothermal process due to the burning $\mathrm{Cu}$-BTC which caused the collapsing $\mathrm{Cu}-\mathrm{BTC}$ structure.

\subsection{Electrochemical performance of $\mathrm{Cu}-\mathrm{BTC} / \mathrm{ErGO} / \mathrm{GCE}$}

Before using Cu-BTC/ErGO as a modifier of detection of 2,4-DP, DPVs of $12 \mu \mathrm{M}$ of 2,4-DCP on different electrodes: bare GCE, GO/GCE, ErGO/GCE, Cu-BTC/GO/GCE and $\mathrm{Cu}-\mathrm{BTC} / \mathrm{ErGO} / \mathrm{GCE}$ were recorded in $\mathrm{PBS} \mathrm{pH}=7$ (Fig. $6 \mathrm{~S} \dagger$ ). After baseline subtraction, oxidation peaks of $12 \mu \mathrm{M}$ of 2,4-DCP were observed on all tested materials. Four smaller peaks at $0.59 \mathrm{~V}, 0.66 \mathrm{~V}$, $0.72 \mathrm{~V}$ and $0.81 \mathrm{~V}$ received from GCE, Cu-BTC/GO/GCE, Er/GO/ GCE and GO/GCE respectively. The highest peak at about $0.65 \mathrm{~V}$ assigned to 2,4-DCP oxidation on $\mathrm{Cu}-\mathrm{BTC} / \mathrm{ErGO} / \mathrm{GCE}$. Currents measured in this case are about 1.46, 1.42, 1.65 and 3.8 times higher than that using GCE, Cu-BTC/GO/GCE, ErGO/GCE and

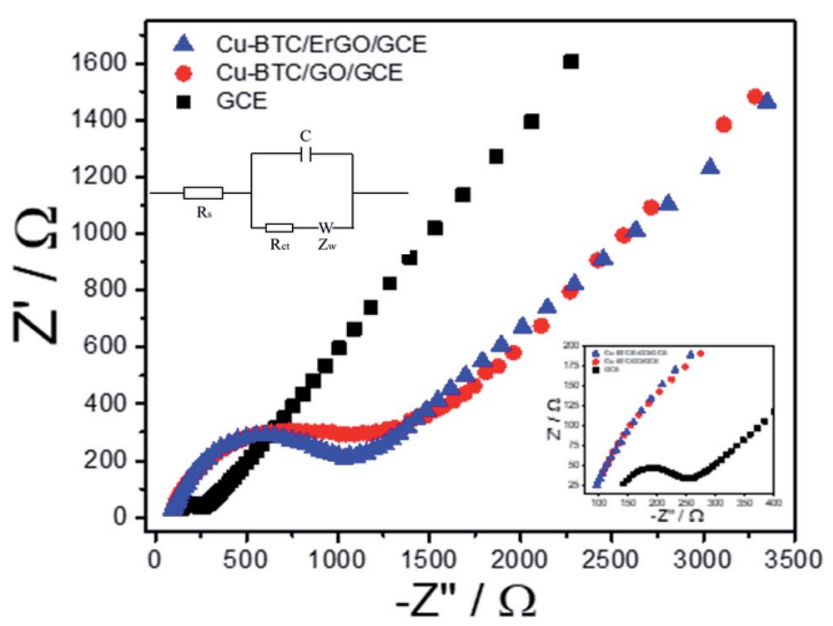

Fig. 5 Nyquist diagrams of GCE, Cu-BTC/GO/GCE and $\mathrm{Cu}-\mathrm{BTC} /$ ErGO/GCE in the solution containing $5 \mathrm{mM} \mathrm{Fe}(\mathrm{CN})_{6}^{3-/ 4-}$ and $0.1 \mathrm{M}$ $\mathrm{KCl}$. Parameters as follow: frequency range from $0.01 \mathrm{~Hz}$ to $10000 \mathrm{~Hz}$, initiative potential: $0.23 \mathrm{~V}$ amplitude: $10 \mathrm{mV}$ and quiet time of $5 \mathrm{~s}$. Its equivalent circuit is in inset. 


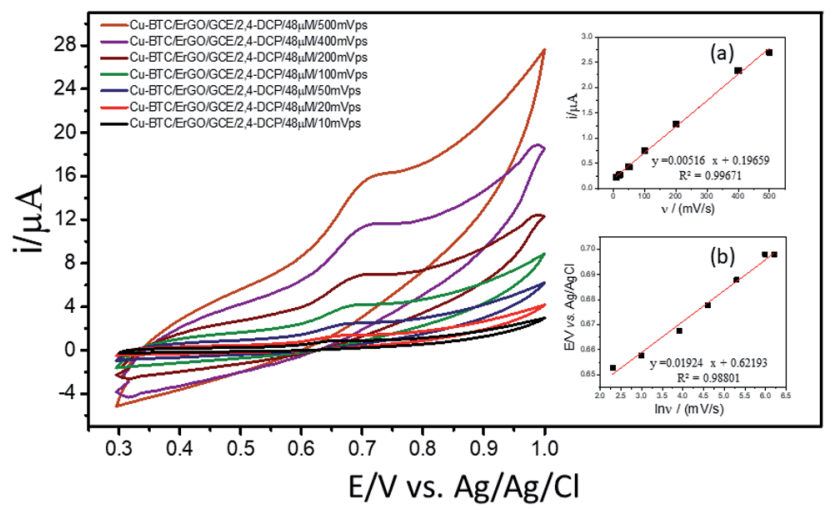

Fig. $6 \mathrm{CVs}$ of 2,4-DCP $48 \mu \mathrm{M}$ in PBS pH 7 recorded on Cu-BTC/ ErGO/GCE at different scan rates ( $\nu): 10,20,50,100,200,400$ and $500 \mathrm{mV} \mathrm{s}^{-1}$. Inset: relationship between anodic peak currents and scan rate (a); peak position and scan rate (b).

GO/GCE respectively. Therefore, $\mathrm{Cu}-\mathrm{BTC} / \mathrm{ErGO}$ was selected for further investigation.

Electrochemical behavior of $\mathrm{Cu}-\mathrm{BTC} / \mathrm{GO} / \mathrm{GCE}$ before and after reduction were tested with electrochemical impedance spectroscopy (EIS) and cyclic voltammetry (CVs) using $\mathrm{Fe}(\mathrm{CN})_{6}{ }^{3-/ 4-}$ couple as the electrochemical redox probes. It is known that the semicircle at higher frequencies is associated with the charge transfer resistance $\left(R_{\mathrm{ct}}\right)$ whereas the linear part at lower frequencies is related to the diffusion process. Fig. 5 shows the impedance spectra of bare GCE, Cu-BTC/GO/GCE and $\mathrm{Cu}-\mathrm{BTC} / \mathrm{ErGO} / \mathrm{GCE}$ in solution containing $5 \mathrm{mM}$ $\mathrm{Fe}(\mathrm{CN})_{6}{ }^{3-/ 4-}$ and $0.1 \mathrm{M} \mathrm{KCl}$.

In the Nyquist diagram (Fig. 5), the bare GCE exhibited a relatively low electron transfer resistance $\left(R_{\mathrm{ct}}=146.3 \Omega\right)$ with a small semicircle (refer to in inset for further detail). After the deposition of $\mathrm{Cu}-\mathrm{BTC} / \mathrm{GO}$, the electron transfer rate dramatically dropped, which resulted from an increase of the charge transfer resistance $\left(R_{\mathrm{ct}}=1407.7 \Omega\right)$ due to the low conductivity of $\mathrm{Cu}-\mathrm{BTC} / \mathrm{GO}$. Once the $\mathrm{Cu}-\mathrm{BTC} / \mathrm{GO}$ is electrochemically reduced to $\mathrm{Cu}-\mathrm{BTC} / \mathrm{ErGO}$, the resulted $R_{\mathrm{ct}}$ decreases $\left(R_{\mathrm{ct}}=\right.$ $1079.7 \Omega$ ). Consequently, electrical conductivity of $\mathrm{Cu}-\mathrm{BTC} /$ ErGO attached on GCE was improved. All the results further demonstrate that the modified electrode is successfully fabricated. This result is in a good agreement with CV tests (Fig. 7S $\dagger$ ). Accordingly, the electron transfer properties were evaluated in presence of an inner sphere redox probe (i.e. $\mathrm{Fe}(\mathrm{CN})_{6}{ }^{3-}$ ). From electrochemical standpoint, the electron transfer in inner sphere systems requires strong interaction between the redox probe and the electrode surface. While bare GCE depicted a well - defined reversible redox system with a peak-to-peak separation $\left(\Delta E_{\mathrm{p}}\right)$ of $60 \mathrm{mV}$, the $\mathrm{Cu}-\mathrm{BTC} / \mathrm{GO} / \mathrm{GCE}$ exhibits extremely low electron transfer rate with a full blocking effect, resulted from the absence of faradaic signal of $\mathrm{Fe}(\mathrm{CN})_{6}{ }^{3-/ 4-}$ in the studied electrochemical window $\left(\Delta E_{\mathrm{p}}>1.5 \mathrm{~V}\right)$. After reduction to $\mathrm{Cu}-$ $\mathrm{BTC} / \mathrm{ErGO} / \mathrm{GCE}$, the resulted electrode displays intermediate electron transfer rate $\left(\Delta E_{\mathrm{p}}=200 \mathrm{mV}\right)$ highlighting an increase of electrical conductivity compared to the non-reduced composite (Fig. 7S $\dagger$ ).
3.4.1 Effects of scan rate $(\boldsymbol{\nu})$. The electroactive surface area (ECSA) of the electrodes were also tested by scanning CV curves at different scan rates in the range from $10-500 \mathrm{mV} \mathrm{s}^{-1}$. A bare GCE was used for comparison. A reduction peak can be observed at about $0.24 \mathrm{~V}$ on the $\mathrm{CV}$ curves of the electrodes in $\mathrm{K}_{3}\left[\mathrm{Fe}(\mathrm{CN})_{6}\right]$ solution. This peak corresponds to the reduction of $\mathrm{Fe}($ III $) \rightarrow \mathrm{Fe}(\mathrm{II})$. The oxidation peak appears on the backward curves at about $0.09 \mathrm{~V}$, corresponding to $\mathrm{Fe}(\mathrm{II}) \rightarrow \mathrm{Fe}(\mathrm{III})$ oxidation (Fig. 8S $\dagger$ ). Both anodic and cathodic peak heights are proportional to the square root of the scanning rate $\left(i_{\mathrm{p}, \mathrm{a}}=\right.$ $2.2715 \operatorname{sqrt}(\nu)+7.54$ with $\left.R^{2}=0.9279\right)$. These peak heights were used for further calculations of effective surface areas. At $100 \mathrm{mV} \mathrm{s}^{-1}$, the ECSA was estimated (from Randle-Sevcik equation) to be 0.0568 and $0.0265 \mathrm{~cm}^{2}$ for bare and modified electrodes, respectively. Observed peaks appeared in Fig. $8 \mathrm{~S} \dagger$ at $0.711 \mathrm{~V}$ and $0.689 \mathrm{~V}$, which peak heights are proportional to scan rate as well. It was suggested that the second redox couple is related to the unexpected formation of iron oxide particles.

For investigation of kinetics of electrochemical oxidation of 2,4-DCP on Cu-BTC/ErGO/GCE, the effect of scan rate on electrochemical signals was recorded with 10, 20, 50, 100, 200, 400 and $500 \mathrm{mV} \mathrm{s}^{-1}$ (Fig. 6) in PBS at pH 7. As seen in Fig. 6 (inset (a)), oxidation peak currents increased linearly with the increase of scan rate with the regression equation $i_{\mathrm{p}, \mathrm{a}}=0.0052 \times \nu+$ $0.1966\left(R^{2}=0.9967\right)$, which suggests an adsorption controlled kinetic process on the modified electrode surface $\mathrm{Cu}-\mathrm{BTC} /$ ErGO/GCE. ${ }^{\text {9,11,12 }}$ As seen in Fig. 6, the oxidation peak potential $\left(E_{\mathrm{p}, \mathrm{a}}\right)$ slightly shifted to more positive potentials with the increasing of the scan rate. The dependence between $E_{\mathrm{p}, \mathrm{a}}$ and the $\ln (v)$ was shown in the inset of Fig. 6(b) in linear regression equation of $E_{\mathrm{p}, \mathrm{a}}(V)=0.0192 \ln (v)+0.6219\left(R^{2}=0.9880\right)$.

As for an adsorption-controlled and totally irreversible electrode process, the relationship between the potential $\left(E_{\mathrm{p}, \mathrm{a}}\right)$ and the natural logarithm of scan rate $(\ln (v))$ could be expressed as follows by Laviron: ${ }^{36}$

$$
E_{\mathrm{p}, \mathrm{a}}=E^{\mathrm{o}}+\left(\frac{R T}{\alpha n F}\right) \ln \left(\frac{R T k^{\mathrm{o}}}{\alpha n F}\right)+\left(\frac{R T}{\alpha n F}\right) \ln v
$$

where $v$ is the scan rate, $n$ is the number of electron transferred, $\alpha$ is the electron transfer coefficient, $k^{\mathrm{o}}$ is standard rate constant of the reaction, and $R, F$ and $T$ are gas constant, faraday constant and absolute temperature, respectively. As the slope of

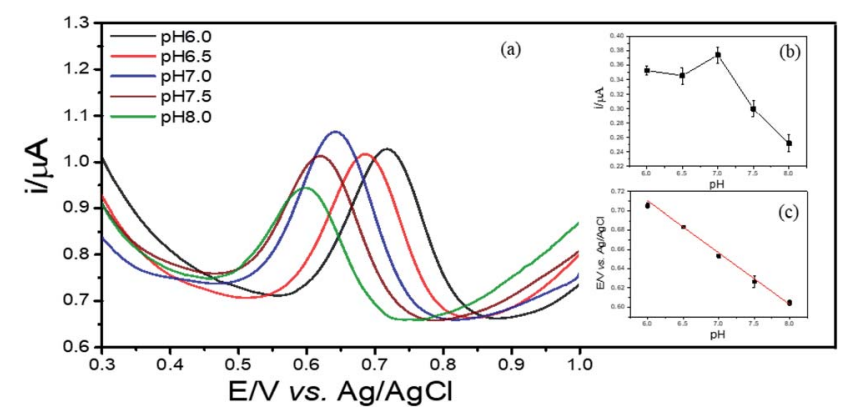

Fig. 7 DPVs of 2,4-DCP on Cu-BTC/ErGO/GCE in PBS pH 7 with different $\mathrm{pH}: 6.0 ; 6.5 ; 7.0 ; 7.5 ; 8.0$ (a), currents varied by $\mathrm{pH}$ (b) and relationship between potentials and $\mathrm{pH}$ (c). 


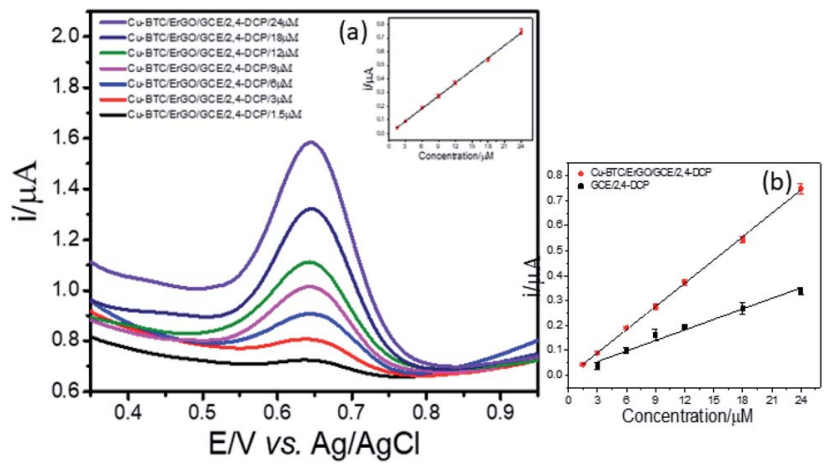

Fig. 8 Voltammograms acquired from 2,4-DCP in the concentration range from 1.5 to $24 \mu \mathrm{M}$ (a) and the variations of peak intensities according to the concentration change using both modified and bare GCE (b).

the plot of $E_{\mathrm{p}, \mathrm{a}}$ versus $\ln (v)$ (equal to $R T / \alpha n F$ ) is 0.0192 , the value of $\alpha n$ was about 1.3. Also from Laviron, ${ }^{36} \alpha$ for an irreversible electrode process is assumed to be 0.5 , therefore, the number of electron transferred $(n)$ for electro-oxidation of 2,4-DCP is around $2 . .^{9,11,12,37}$

\subsection{Optimization of the electrochemical experiment parameters}

3.5.1 Influence of $\mathrm{Cu}-\mathrm{BTC} / \mathrm{GO}$ content. Influence of $\mathrm{Cu}-$ BTC/GO content used for modification was also tested from $0.5 \mathrm{mg} \mathrm{mL}{ }^{-1}, 1.0 \mathrm{mg} \mathrm{mL}^{-1}, 2.0 \mathrm{mg} \mathrm{mL}^{-1}$. The signals of 2,4DCP (Fig. 9S $\dagger$ ) $12 \mu \mathrm{M}$ in PBS $0.1 \mathrm{M}, \mathrm{pH}$ 7, from $0.2 \mathrm{~V}$ to $1.4 \mathrm{~V}$, accumulation time $240 \mathrm{~s}$ show that at $1 \mathrm{mg} \mathrm{mL}^{-1}$, the curve formed a symmetrical line with the highest current. This content was used for further electrode modifications.

3.5.2 Effect of $\mathbf{~ p H}$. As the electrochemical oxidation of 2,4DCP followed a proton coupled electron transfer (PCET) mechanism, i.e. $2,4-\mathrm{DCP} \rightleftharpoons$ oxidized product $+\mathrm{ne}^{-}+\mathrm{nH}^{+}(n=1$ or 2), the reaction rate is directly depending on the electron flux and the concentration of proton in solution. ${ }^{\mathbf{1 0 , 1 2}}$ Consequently, the $\mathrm{pH}$ becomes one of the key parameters impacting the performance of the presented sensors. DPVs of 2,4-DCP $(C=12$ $\mu \mathrm{M}$ ) were obtained by sweeping the potential from $0.2 \mathrm{~V}-1.4 \mathrm{~V}$ in PBS buffer with $\mathrm{pH}$ ranged from 6.0-8.0 at interval 0.5. As shown in the Fig. 7a, the peak potential is negatively shifted as the $\mathrm{pH}$ of the solution increases. By plotting the variation of peak potential in function of $\mathrm{pH}$ values, a linear relationship is obtained, i.e. $E_{\mathrm{p}, \mathrm{a}}=-0.0547 \mathrm{pH}+1.0369, R^{2}=0.9924$. Based on this equation and the number of electrons transferred (about 2, above), the electrochemical oxidation of 2,4-DCP at Cu-BTC/ ErGO/GCE is a two-electron and two-proton process, which is in good agreement with previous publications., ${ }^{9,11,12,37}$

3.5.3 Effects of accumulation time. The accumulation conditions are essential to improve electrochemical signals recorded during adsorption-controlled electrochemical reactions such as electro-oxidation of 2,4-DCP. Here, the DPV voltammograms from $0.2 \mathrm{~V}-1.4 \mathrm{~V}$ of interested analyte at $3 \mu \mathrm{M}$ were recorded at different accumulation time (60-480 s) with interval of $60 \mathrm{~s}$ in PBS electrolyte ( $\mathrm{pH}$ 7.0). Bare GCE was also used for comparison with modified electrode (Fig. 10S $\dagger$ ). As indicating in this Fig. 9S, $\uparrow$ the saturation of 2,4-DCP on both modified and unmodified electrodes was reached at an accumulation time of $240 \mathrm{~s}$. Two other concentrations of 2,4-DCP (6 $\mu \mathrm{M}$ and $12 \mu \mathrm{M})$ in a similar condition were investigated and

Table 1 Comparison of sensing performances of electrochemical sensors for detection of 2,4-DCP ${ }^{a}$

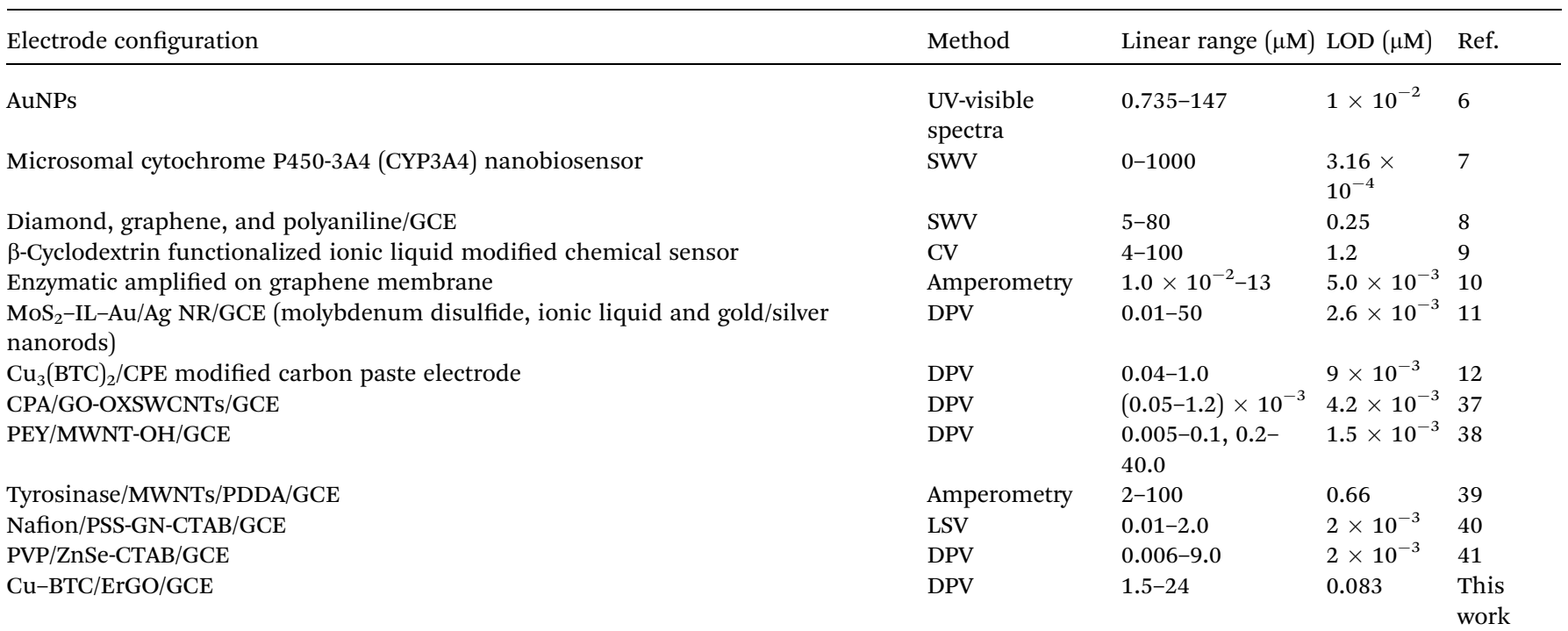

${ }^{a}$ AuNPs $=$ gold nano particles, $\mathrm{CPE}=$ carbon paste electrode, NPs $=$ nanoparticles, ILs: ionic liquids, NRs $=$ nanorods, $\mathrm{BTC}=$ benzenetricarboxylic, $\mathrm{GO}=$ graphene oxide, $\mathrm{ErGO}=$ electrochemical reduced graphene oxide, GCE = glassy carbon electrode; SWV $=$ square wave voltammetry, DPV $=$ differential pulse voltammetry, CV = cyclic voltammetry, LSV = linear sweep voltammetry, OXSWCNTs = oxidized carbon single wall carbon nanotubes, PEY $=$ poly(eosin Y), MWNT $=$ multi-walled carbon nanotubes, PDDA $=$ polydiallyldimethylammonium chloride, PSS $=$ poly(sodium-4-styrenesulfonate), $\mathrm{GN}=$ graphene, $\mathrm{CTAB}=$ cetyltrimethylammonium bromide, $\mathrm{PVP}=$ polyvinylpyrrolidone. 
Table 2 Determined 2,4-DCP concentrations spiked in lake water using $\mathrm{Cu}-\mathrm{BTC} / \mathrm{ErGO} / \mathrm{GCE}$. The recovery in each case is also shown

\begin{tabular}{lllc}
\hline & $24 \mathrm{DCP}(\mu \mathrm{M})$ & & \\
\cline { 2 - 4 } Sample & Added & Found & Recovery (\%) \\
\hline Lake water & 3.00 & $3.13 \pm 0.47$ & 104.15 \\
& 4.50 & $4.43 \pm 0.10$ & 99.48 \\
& 6.00 & $5.83 \pm 0.36$ & 97.17
\end{tabular}

$240 \mathrm{~s}$ of adsorption time is observed as optimized duration to achieve maximum electrochemical signals (Fig. 11S†).

\subsection{Detection of 2,4-DCP using $\mathrm{Cu}-\mathrm{BTC} / \mathrm{ErGO} / \mathrm{GCE}$}

3.6.1 Calibration curve. Fig. 8 shows voltammograms of all the samples measured using $\mathrm{Cu}-\mathrm{BTC} / \mathrm{ErGO} / \mathrm{GCE}$ under optimized conditions. 2,4-DCP peak heights increased with increase in concentrations with the regression equation of $i(\mu \mathrm{A})=$ 0.0310. $C(\mu \mathrm{M})-0.003$ and relative standard deviation (RSD) is $3.52 \%$ (Fig. 8(a)). Even the electron transfer at modified electrode was not as good as bare one (section 3.2), the good adsorption of 2,4-DCP into porous structure of $\mathrm{Cu}-\mathrm{BTC} / \mathrm{GO}$ material must be the reason for the enhancement in current responses. For each concentration, the experiment was repeated three times using three separately prepared $\mathrm{Cu}-\mathrm{BTC} /$ ErGO/GCE.

Next, LOD was calculated based on the response curve in the figure $\left(\mathrm{LOD}=3.3 \times \frac{\mathrm{SD}}{b} ; \mathrm{SD}\right.$ : standard deviation of ordinate intercept, $b$ : slope of regression line). The LOD were $0.083 \mu \mathrm{M}$ for detection of 2,4-DCP in PBS ( $\mathrm{pH} 7$ ). Although the achieved LOD is not best in comparison with those reported in the previous studies (Table 1), it is clearly acceptable and in a toplevel group.

3.6.2 Reproducibility, repeatability and durability. The reproducibility was tested and the error bars in the response curve correspond to the standard deviations of peak intensities acquired using the eight separate sensors (Fig. 12S $\dagger$ ). The magnitudes of error bars are quite small and the average relative standard deviations (RSDs) in the measurements of 2,4-DCP are $2.55 \%$, thereby confirming the reproducible formation of $\mathrm{Cu}-\mathrm{BTC} / \mathrm{GO}$ on GCE. The repeatability was also evaluated by consecutively measuring a sample containing $12 \mu \mathrm{M}$ 2,4-DCP five times using one sensor. No decreases of peak intensities were observed during the scans, and resulting RSDs of 2,4-DCP peak intensities were $2.03 \%$, respectively (Fig. $13 \mathrm{~S} \dagger$ ). The result confirms the superior surface stability of Cu-BTC/ErGO/GCE.

The durability of the prepared electrode was tested in the presence of $12 \mu \mathrm{M}$ 2,4-DCP and retained a response of $96.96 \%$ and $93.85 \%$ after 1 and 2 weeks respectively (Fig. 14S $\dagger$ ). It is worth noting that the sensing electrodes were stored in air without any specific protection.

3.6.3 Interference study. Finally, the selectivity of measurements was evaluated by observing the electrochemical signals of 2,4-DCP samples in presence of $\mathrm{Hg}^{2+} / \mathrm{Pb}^{2+} / \mathrm{Mg}^{2+} / \mathrm{As}^{3+}$ or 4-nitrophenol, bisphenol A, hydroquinone and dopamine as interferants. The concentrations of interferants were designedly fixed at $60 \mu \mathrm{M}$ which is five times greater than 2,4-DCP concentration. As displayed in the Fig. 15S, $\uparrow$ there are no significant changes in current intensity (only less than $10 \%$ peak current of 2,4-DCP decreased with presence of bisphenol A, hydroquinone and dopamine), suggesting the absence of interference effect due to other compounds.

3.6.4 Real sample analysis (lake water). Finally, $\mathrm{Cu}-\mathrm{BTC} /$ ErGO/GCE was further used to determine 2,4-DCP concentrations in real samples collected from West Lake (Hanoi, Vietnam) according to Standard Methods for Examination of Water and Waste Water (SMEWW). The samples were directly analyzed without any further treatment. Table 2 shows the determined 2,4-DCP concentrations spiked in the lake water using $\mathrm{Cu}-\mathrm{BTC} / \mathrm{ErGO} / \mathrm{GCE}$ and the calculated recoveries (Fig. 16S $\dagger$ ).

The concentration determinations using $\mathrm{Cu}-\mathrm{BTC} / \mathrm{ErGO} / \mathrm{GCE}$ were accurate with a recovery range of $99.48-104.15 \%$. Therefore, the detection performance of $\mathrm{Cu}-\mathrm{BTC} / \mathrm{ErGO} / \mathrm{GCE}$ was acceptable for this purpose.

\section{Conclusion}

In the present work, a $\mathrm{Cu}-\mathrm{BTC} / \mathrm{GO}$ material was prepared using hydrothermal approach and then utilized as electrode modifier for electrochemical determination of 2,4-DCP in aqueous solutions. The as-synthesized material shows nanoscale porous structures with surface area, pore volume and pore size of $\mathrm{Cu}-$ BTC/GO were $1591 \mathrm{~m}^{2} \mathrm{~g}^{-1}, 1.485 \mathrm{~cm}^{3} \mathrm{~g}^{-1}$ and $3.34 \mathrm{~nm}$, respectively. Developed sensors by modifying the electrode surface with such a porous material on GCE followed by electrochemical reduction was used for detection of 2,4-DCP with detection limits of $0.083 \mu \mathrm{M}$ and linear range from 1.5-24 $\mu \mathrm{M}$. Sensor-to-sensor reproducibility was estimated by measuring eight separate prepared $\mathrm{Cu}-\mathrm{BTC} / \mathrm{ErGO} / \mathrm{GCE}$ sensors and RSDs of the peak intensities of 2,4 -DCP were $2.55 \%$, thereby indicating the superior sensor-to-sensor reproducibility. The repeatability was also evaluated by consecutively measuring a sample containing $12 \mu \mathrm{M}$ 2,4-DCP five times using one sensor and RSDs of 2,4-DCP peak intensities were $2.03 \%$. Real lake water samples were analyzed, the determined concentrations were in good recoveries, which ranged from 97.17.2-104.15\%. This is a valuable merit when considering practical field application of the sensor. Therefore, a small and portable analytical device embedded with an Cu-BTC/ErGO/GCE sensor as a promising component is under development for on-site measurement of 2,4-DCP concentrations in water samples.

\section{Conflicts of interest}

There are no conflicts to declare.

\section{Acknowledgements}

This research is funded by Vietnam Academy of Science and Technology, under grant number KHCBHH.01/19-21. 


\section{References}

1 Y. Liang, L. Yu, R. Yang, X. Li, L. Qu and J. Li, Sens. Actuators, $B, 2017,240,1330-1335$.

2 X. Fang, B. Zong and S. Mao, Nano-Micro Lett., 2018, 10, 64. 3 F. Galán-Cano, R. Lucena, S. Cárdenas and M. Valcárcel, J. Chromatogr. A, 2012, 1229, 48-54.

4 Y. Li, Y. Jiao, Y. Guo and Y. Yang, Anal. Methods, 2013, 5, 5037-5043.

5 Q. Liu, J. Shi, L. Zeng, T. Wang, Y. Cai and G. Jiang, J. Chromatogr. A, 2011, 1218, 197-204.

6 Q. Feng, H. Li, Z. Zhang and J. M. Lin, Analyst, 2011, 136, 2156-2160.

7 J. Zhang, J. Lei, H. Ju and C. Wang, Anal. Chim. Acta, 2013, 786, 16-21.

8 M. G. Peleyeju, A. O. Idris, E. H. Umukoro, J. O. Babalola and O. A. Arotiba, ChemElectroChem, 2017, 4, 1074-1080.

9 F. L. Mohd Rasdi, S. Mohamad, N. S. Abdul Manan and H. R. Nodeh, RSC Adv., 2016, 6, 100186-100194.

10 Q. Xu, X. Li, Y.-e. Zhou, H. Wei, X.-Y. Hu, Y. Wang and Z. Yang, Anal. Methods, 2012, 4, 3429-3435.

11 H. Huang, M. Wang, Y. Wang, X. Li, Z. Niu, X. Wang and J. Song, Microchim. Acta, 2018, 185, 292.

12 S. Dong, G. Suo, N. Li, Z. Chen, L. Peng, Y. Fu, Q. Yang and T. Huang, Sens. Actuators, B, 2016, 222, 972-979.

13 W. Liu and X.-B. Yin, TrAC, Trends Anal. Chem., 2016, 75, 8696.

14 Y. Cao, Z. Wu, T. Wang, Y. Xiao, Q. Huo and Y. Liu, Dalton Trans., 2016, 45, 6998-7003.

15 Y. Cao, L. Wang, C. Shen, C. Wang, X. Hu and G. Wang, Sens. Actuators, B, 2019, 283, 487-494.

16 L. Ji, Q. Cheng, K. Wu and X. Yang, Sens. Actuators, B, 2016, 231, 12-17.

17 B. Ma, H. Guo, M. Wang, L. Li, X. Jia, H. Chen, R. Xue and W. Yang, Electroanalysis, 2019, 31, 1002-1008.

18 D. Brondani, E. Zapp, R. da Silva Heying, B. de Souza and I. Cruz Vieira, Electroanalysis, 2017, 29, 2810-2817.

19 Q. Chen, X. Li, X. Min, D. Cheng, J. Zhou, Y. Li, Z. Xie, P. Liu, W. Cai and C. Zhang, J. Electroanal. Chem., 2017, 789, 114122.
20 J. Li, J. Xia, F. Zhang, Z. Wang and Q. Liu, Talanta, 2018, 181, 80-86.

21 X. Wang, Q. Wang, Q. Wang, F. Gao, F. Gao, Y. Yang and H. Guo, ACS Appl. Mater. Interfaces, 2014, 6, 11573-11580.

22 H. Miyasaka, Acc. Chem. Res., 2013, 46, 248-257.

23 Q. Wang, Y. Yang, F. Gao, J. Ni, Y. Zhang and Z. Lin, ACS Appl. Mater. Interfaces, 2016, 8, 32477-32487.

24 C. Petit, B. Mendoza and T. J. Bandosz, Langmuir, 2010, 26, 15302-15309.

25 P. Srimuk, S. Luanwuthi, A. Krittayavathananon and M. Sawangphruk, Electrochim. Acta, 2015, 157, 69-77.

26 N. I. Zaaba, K. L. Foo, U. Hashim, S. J. Tan, W.-W. Liu and C. H. Voon, Procedia Eng., 2017, 184, 469-477.

27 F. T. Johra and W.-G. Jung, Appl. Surf. Sci., 2015, 357, 19111914.

28 X. Zhao, S. Liu, Z. Tang, H. Niu, Y. Cai, W. Meng, F. Wu and J. P. Giesy, Sci. Rep., 2015, 5, 11849.

29 X. Zhang, Z. Zhan, Z. Li and L. Di, Catalysts, 2017, 7, 106.

30 Q. Fu, K. Xie, S. Tan, J. M. Ren, Q. Zhao, P. A. Webley and G. G. Qiao, Chem. Commun., 2016, 52, 12226-12229.

31 A. K. Kar and R. Srivastava, Inorg. Chem. Front., 2019, 6, 576589.

32 T. Noor, M. Ammad, N. Zaman, N. Iqbal, L. Yaqoob and H. Nasir, Catal. Lett., 2019, 149, 3312-3327.

33 S. Yang, Q. Zou, T. Wang and L. Zhang, J. Membr. Sci., 2019, 569, 48-59.

34 Y. Chen, D. Lv, J. Wu, J. Xiao, H. Xi, Q. Xia and Z. Li, Chem. Eng. J., 2017, 308, 1065-1072.

35 T. Azizi Vahed, M. R. Naimi-Jamal and L. Panahi, New J. Chem., 2018, 42, 11137-11146.

36 E. Laviron, J. Electroanal. Chem., 1974, 52, 355-393.

37 D. F. Katowah, G. I. Mohammed, D. A. Al-Eryani, T. R. Sobahi and M. A. Hussein, PLoS One, 2020, 15(6), e0234815.

38 X. Zhu, K. Zhang, C. Wang, J. Guan, X. Yuan and B. Li, Sci. Rep., 2016, 6, 38657.

39 L. Kong, S. Huang, Z. Yue, B. Peng, M. Li and J. Zhang, Microchim. Acta, 2009, 165, 203-209.

40 J. Li, D. Miao, R. Yang, L. Qu and P. d. B. Harrington, Electrochim. Acta, 2014, 125, 1-8.

41 J. Li, X. Li, R. Yang, L. Qu and B. Harrington Pde, Anal. Chim. Acta, 2013, 804, 76-83. 